\title{
Chronic Nicotine Alters Corticostriatal Plasticity in the Striatopallidal Pathway Mediated By NR2B-Containing Silent Synapses
}

\author{
Jianxun Xia', Allison M Meyers' and Jeff A Beeler", \\ 'Department of Psychology, Queens College and The Graduate Center, City University of New York, Flushing, NY, USA
}

\begin{abstract}
Smoking is the leading cause of preventable death in the United States and success rates for quitting remain low. High relapse rates are attributed to pervasive nicotine-reinforced associative learning of incentive cues that is highly resistant to extinction. Why such learning is so persistent is poorly understood but may arise as a consequence of neuroadaptations in synaptic plasticity induced by chronic nicotine. We used whole-cell patch clamp recording to investigate the effect of chronic nicotine (cNIC) on synaptic plasticity in dopamine D2 receptorexpressing medium-spiny neurons in the indirect, striatopallidal pathway in dorsolateral striatum. Mice exposed to cNIC exhibited longterm potentiation in response to high-frequency stimulation instead of the expected depression. cNIC decreased baseline AMPA/NMDA ratio, arising from increased NMDA currents enriched in the NR2B subunit with a concomitant upregulation of NMDA-only, silent synapses. These data demonstrate that $\mathrm{CNIC}$ can increase silent synapses in MSNs, as observed with cocaine and opiates, and alter the regulation of corticostriatal plasticity. Prior work has characterized cocaine- and morphine-induced upregulation of silent synapses in the ventral striatum; we show it can occur in the dorsal striatum, a region associated with later stages of addiction, craving, and cue-induced relapse.

Neuropsychopharmacology (2017) 42, 23I4-2324; doi:I0.I038/npp.2017.87; published online 31 May 2017
\end{abstract}

\section{INTRODUCTION}

Smoking represents a major public health problem and is the leading cause of preventable death in the United States (US Department of Health and Human Services, 2014). Despite significant reductions in smoking rates over recent decades, 42.1 million continue to smoke in the United States alone ( $18 \%$ of adults), with new smokers joining daily (US Department of Health and Human Services, 2014). Rates of successful quitting remain very low, estimated at $\sim 9-15 \%$ for heavy smokers (Pierce et al, 2012).

Nicotine, the putative addictive agent in tobacco, is believed to mediate smoking-reinforced associative learning that underlies the cue-induced craving that makes sustained abstinence difficult (Caggiula et al, 2001; Smolka et al, 2006). It is widely believed that this learning is in some way supraphysiological and highly resistant to extinction (Di Chiara, 2000; Hyman et al, 2006), though the physiological mechanisms that underlie the persistence of nicotinereinforced learning are poorly understood (Hyman et al, 2006).

*Correspondence: Dr JA Beeler, Department of Psychology, Queens College and The Graduate Center, CUNY, 65-30 Kissena Blvd, Queens, NY I|367, USA, Tel: +7|8 570 05|7, Fax: +773 793 2588, E-mail: jbeeler@qc.cuny.edu

Received 5 November 2016; revised 22 April 2017; accepted 25 April 2017; accepted article preview online 2 May 2017
The acute effects of nicotine, including nicotine-induced dopamine release believed to underlie its addictive properties (Dani et al, 2001; Di Chiara, 2000; Mansvelder and McGehee, 2000), have been well studied. Chronic nicotine (cNIC), however, induces neuroadaptations that have been less well characterized. For example, although acute nicotine increases extracellular dopamine, cNIC substantially downregulates evoked dopamine release (Exley et al, 2013; Koranda et al, 2014; Perez et al, 2012). In humans, fMRI studies suggest that cNIC induces neuroadaptations that are independent of acute nicotine state, including reduced reward sensitivity (Rose et al, 2013) and increased cue-reactivity (McClernon et al, 2005). Whether cNIC induces alterations in the regulation of corticostriatal synaptic plasticity has not been investigated. Here we chronically administer nicotine to mice in their drinking water and assess corticostriatal plasticity in striatopallidal medium-spiny neurons of the indirect pathway (iMSNs) in the dorsolateral striatum (DLS). Although the nucleus accumbens (NAc) is widely associated with establishing and maintaining addictive behaviors, in the later stages of addiction, the DLS-a key substrate for habit learning and automaticity (Yin and Knowlton, 2006) - comes into play contributing to cue-induced cravings that promote relapse (Everitt and Robbins, 2016; Gerdeman et al, 2003). Moreover, the dopamine D2 receptor, expressed on iMSNs, plays a pivotal role in behavioral flexibility (Klanker et al, 2013), suggesting this circuit may be critical to 
understanding behavioral inflexibility associated with nicotine addiction.

\section{MATERIALS AND METHODS}

\section{Animals}

Adult mice of 11-12 weeks old were used for all experiments. To identify D2-expressing striatopallidal MSNs, mice were hemizygous for a transgene expressing enhanced green fluorescent protein under control of the Drd2 promoter (D2-EGFP, bacterial artificial chromosome) and backcrossed onto a C57BL/6 background ( $>10$ generations). All animal experiments were approved by the Queens College, CUNY, Institutional Animal Care and Use Committee in accordance with National Institutes of Health Guidelines for the responsible use of animals in research.

\section{cNIC Exposure}

Mice were exposed to $100 \mu \mathrm{g} / \mathrm{ml}$ (free base) nicotine via their drinking water for 3 weeks starting at postnatal 60 days. This dose did not alter daily water intake or body weight, as reported previously (Koranda et al, 2014, 2016). Mice were maintained on this schedule of nicotine dosing until they were removed from their homecage, anesthetized, and prepared for electrophysiological recordings.

\section{Slice Preparation}

Mice were anesthetized with isoflurane and decapitated. The brain was quickly removed from the cranial cavity and placed into an ice-cold $\left(4^{\circ} \mathrm{C}\right)$ sucrose-containing artificial cerebrospinal fluid (ACSF), in mM: 200 sucrose, $2.5 \mathrm{KCl}$, $10 \mathrm{MgSO}_{4}, 1.25 \mathrm{NaH}_{2} \mathrm{PO}_{4}, 26 \mathrm{NaHCO}_{3}, 10$ glucose, $7 \mathrm{Na}$ ascorbate, $3 \mathrm{Na}$-pyruvate, and maintained at $\mathrm{pH} 7.4$ by oxygenating with $95 \% \mathrm{O}_{2} / 5 \% \mathrm{CO}_{2}$. Coronal slices $(300 \mu \mathrm{m})$ containing dorsal striatum were cut using a VT1000 S vibratome (Leica Biosystems, Buffalo Grove, IL). Slices were immediately transferred and incubated for at least $60 \mathrm{~min}$ in a holding chamber at $30-32^{\circ} \mathrm{C}$ in oxygenated ACSF containing, in mM: $125 \mathrm{NaCl}, 2.5 \mathrm{KCl}, 2 \mathrm{CaCl}_{2}, 1 \mathrm{MgCl}_{2}$, $1.25 \mathrm{NaH}_{2} \mathrm{PO}_{4}, 26 \mathrm{NaHCO}_{3}, 12.5$ glucose, and $1 \mathrm{Na}-$ ascorbate, continuously bubbled with $95 \% \mathrm{O}_{2} / 5 \% \mathrm{CO}_{2}$. Then the slices were incubated at room temperature $\left(22-26^{\circ} \mathrm{C}\right)$ during the remaining period of experiments.

\section{Electrophysiology}

Single hemispheric corticostriatal slices were transferred into the recording chamber and superfused with ACSF without $\mathrm{Na}$-ascorbate at a constant flow rate of $1.5-2 \mathrm{ml} / \mathrm{min}$. The temperature of the ACSF was maintained at $30 \pm 1{ }^{\circ} \mathrm{C}$ with an automatic temperature controller (Warner Instrument, Hamden, CT). Whole-cell patch clamp recordings from EGFP-labeled D2-expressing MSNs were performed as described previously (Augustin et al, 2014). Recording pipettes with resistance of 3-7 M $\Omega$ when filled with an internal solution containing, in mM: $120 \mathrm{CsMeSO}_{3}, 15 \mathrm{CsCl}$, $8 \mathrm{NaCl}, 0.2$ EGTA, 10 HEPES, $2 \mathrm{Mg}$-ATP, $0.3 \mathrm{Na}$-GTP, 10 TEA, 5 QX-314, adjusted to $\mathrm{pH} 7.3$ with $\mathrm{CsOH}$. Picrotoxin $(50 \mu \mathrm{M})$ was added to ACSF to block $\mathrm{GABA}_{\mathrm{A}}$ receptor- mediated synaptic currents. EPSCs were recorded using a Multiclamp 700B amplifier at a holding potential of $-70 \mathrm{mV}$ unless otherwise noted. Miniature EPSCs were acquired (3 min samples, gap-free recording) with tetrodotoxin $(10 \mu \mathrm{M})$ applied in addition to picrotoxin and analyzed using miniAnalysis (Synaptosoft). NMDAR-mediated com-

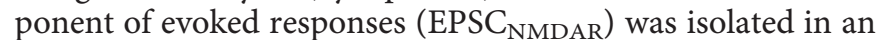
$\mathrm{Mg}^{2+}$-free ACSF containing the AMPAR antagonist NBQX $(5 \mu \mathrm{M})$. To assess NMDAR I-V curve, the EPSC NMDAR was recorded at different holding potentials from -80 to $+40 \mathrm{mV}$ with a $20 \mathrm{mV}$ increment in the normal ACSF. Data were filtered at $2 \mathrm{kHz}$, digitized at $5 \mathrm{kHz}$ using a Digidata 1550, and collected with pCLAMP 10.4 software (Molecular Devices, Sunnyvale, CA) for off-line analysis. Series resistance $(<25 \mathrm{M} \Omega)$ was recorded and monitored throughout the recording. Cells were discarded if these values changed by $>20 \%$ during the experiment.

A bipolar twisted stainless steel electrode with a $500 \mu \mathrm{m}$ tip separation was placed in the corpus callosum or striatum dorsolaterally to the recording location to stimulate excitatory corticostriatal afferent fiber. Paired test pulses separated by $50 \mathrm{~ms}$ were delivered via a Master- 9 stimulator (A.M.P.I., Jerusalem, Israel) at a frequency of $0.05 \mathrm{~Hz}$. Stimulus intensity $(0.1-1 \mathrm{~mA}, 100 \mu \mathrm{s}$ duration) was adjusted to produce EPSC amplitudes between 200-400 pA. Highfrequency stimulation consists of four $1 \mathrm{~s}, 100 \mathrm{~Hz}$ trains delivered every $10 \mathrm{~s}$ paired with postsynaptic depolarization to $0 \mathrm{mV}$. Paired-pulse ratios were calculated using 10 baseline EPSC measurements and 10 measurements at 30 min post stimulation and calculated as the mean of P2 divided by the mean of P1 (Kim and Alger, 2001). AMPA/ NMDA ratios were determined using two methods: (1) an EPSC was recorded at $+40 \mathrm{mV}$, and then D-APV $(50 \mu \mathrm{M})$ was applied to block NMDARs and obtain the AMPA-only EPSC; the NMDA-mediated EPSC was obtained by digitally subtracting the AMPAR current from the total current. (2) AMPA peak amplitude was determined at $-70 \mathrm{mV}$ holding potential; the NMDA peak amplitude was measured at $+40 \mathrm{mV}$ during a $10 \mathrm{~ms}$ window $30 \mathrm{~ms}$ after the peak of the AMPA current. Minimal stimulation experiments were performed to estimate the percentage of silent synapses by comparing the failure rates of EPSCs at $-70 \mathrm{mV}$ and $+40 \mathrm{mV}$. After evoking a small $(<40 \mathrm{pA})$ EPSC at $-70 \mathrm{mV}$, stimulation intensity was reduced until failures and successes could be clearly distinguished visually and $\sim 50 \%$ failure was observed. A threshold of greater than $5 \mathrm{pA}$ was used as cutoff to classify a response as a success. Percent silent synapses were calculated as $1-\ln \left(\right.$ Failures $\left._{-70 \mathrm{mV}}\right) / \mathrm{ln}$ (Failures $+40 \mathrm{mV})$. All chemicals were purchased from SigmaAldrich (St. Louis, MO) except that NBQX, Ro25-6981, and Naspm purchased from Abcam (Cambridge, MA).

\section{Data Analysis}

All data are reported as mean \pm SEM. LTD/LTP was determined by averaging EPSC amplitudes from 30 to $40 \mathrm{~min}$ following the high-frequency stimulation (HFS) and normalized to the averaged 10-min baseline EPSC amplitude. Statistical difference was evaluated by paired Student's $t$-test for within-group comparison or one-way ANOVA for between-group significance. 


\section{RESULTS \\ cNIC Induces LTP and Loss of Presynaptic LTD in Response to HFS in Striatopallidal MSNs}

To identify iMSNs of the indirect pathway, we used mice expressing EGFP under the control of the Drd2 promoter. Mice hemizygous for this transgene and backcrossed to a C57BL/6 background have been shown to exhibit normal behavior and have been used in prior electrophysiological studies (Augustin et al, 2014). iMSNs have been amply demonstrated to exhibit long-term depression (LTD) in response to HFS (Augustin et al, 2014; Bagetta et al, 2011; Lerner and Kreitzer, 2012), a phenomenon believed to be fundamental to learning and motor facilitation in the indirect cortico-basal ganglia-cortical circuit (Kreitzer and Malenka, 2008; Lovinger, 2010). To determine the effect of cNIC on corticostriatal HFS-LTD, we administered nicotine $(100 \mu \mathrm{g} / \mathrm{ml}$, free base) in homecage drinking water for minimally 21 days (Koranda et al, 2014, 2016). The intermittent exposure over time obtained by administration via drinking water is thought to mimic the intermittent nicotine exposure in human smoking (Matta et al, 2007). Such exposure is believed to induce neuroadaptations that persist independently of the presence of nicotine in the system (Koranda et al, 2014, 2016). Such neuroadaptations independent of withdrawal state have been observed in humans as well (McClernon et al, 2005; Rose et al, 2013).

cNIC and non-nicotine control mice exhibited significantly different responses to HFS (cNIC/no-NIC $\times$ time, $\left.\mathrm{F}_{(1,27)}=16.8, p<.001\right)$. Non-nicotine-treated control mice exhibit the expected LTD in response to HFS paired with postsynaptic depolarization (Figure $1 \mathrm{a}, t_{(11)}=5.51, p<0.001$ ) as well as paired-pulse facilitation (Figure $1 \mathrm{~b}, t_{(11)}=3.12$, $p<0.01$ ), consistent with endocannabinoid-mediated alteration of presynaptic release probability (Choi and Lovinger, 1997). In mice treated with cNIC, HFS induced a long-lasting potentiation (LTP, > $40 \mathrm{~min}$ ) with concomitant loss of LTD (Figure 1a, $t_{(16)}=2.35, p=0.03$ ) and no paired-pulse facilitation (Figure $1 \mathrm{~b}, t_{(16)}=1.84, p=0.08$ ).

A recent report (Abburi et al, 2016) observed reduced probability of release in mice given repeated nicotine injections. Though we observed a loss of presynaptic depression following HFS in the cNIC mice, at baseline we saw no difference in PPR (Figure 1a). To further investigate potential baseline differences in synaptic transmission in the cNIC-treated mice, we did a mini-EPSC analysis (Figure $1 \mathrm{c}-\mathrm{e})$. There was no difference in the cumulative probability distribution of amplitude between the cNIC and nonnicotine-treated mice (Figure 1c, main effect of treatment, $\mathrm{F}_{(1,32)}=0.04, p=0.84$; treatment $\times$ amplitude bin, $\mathrm{F}_{(1,32)}=$ $0.39, p=0.53$; inset, mean amplitude, cNIC, $22.9 \pm 0.13$; nonnicotine, $23.1 \pm 0.2$ ). Although the mean inter-event interval was greater in cNIC mice (Figure 1d, inset, cNIC, $2.005 \mathrm{~s} \pm 0.072$; non-nicotine, $1.695 \mathrm{~s} \pm 0.253)$, this was not statistically significant $\left(\mathrm{F}_{(1,2843)}=0.721, p=0.39\right)$. Consistent with the mean, the cumulative probability of inter-event intervals suggests slightly longer intervals between events in cNIC mice, but again the difference is not significant (Figure 1d, main effect of treatment, $\mathrm{F}_{(1,33)}=1.06, p=0.31$; treatment $\times$ amplitude bin, $\left.\mathrm{F}_{(1,33)}=0.305, p=0.584\right)$. These data indicate no differences in baseline presynaptic release probability or postsynaptic response to miniature release events between cNIC and non-nicotine-treated mice, but a reversal in the direction of synaptic plasticity in response to HFS.

\section{Both D2R Activation and NMDA Blockade is Necessary to Restore Whole-Cell HFS-LTD in cNIC-Treated Mice}

Prior studies have demonstrated that the dopamine D2 receptor (D2R) facilitates HFS-LTD in striatopallidal cells (Augustin et al, 2014; Kreitzer and Malenka, 2007; Shen et al, 2008). In contrast, corticostriatal LTP requires NMDAR activation (Lovinger, 2010; Surmeier et al, 2014). To test for rescue of normal HFS-LTD in the CNIC mice, we applied the D2R agonist quinpirole and the NMDAR antagonist APV. Application of quinpirole $(10 \mu \mathrm{M})$ suppressed whole-cell LTP but did not rescue LTD (Figure 2, cNIC \pm QUIN, treatment $\times$ time, $\left.\mathrm{F}_{(1,26)}=4.9, p<0.05\right)$. Perfusion of APV also blocked whole-cell LTP, again without rescuing LTD (Figure 2, cNIC $\pm \mathrm{APV}$, treatment $\times$ time, $\mathrm{F}_{(1,23)}=8.01$, $p<0.01)$. Though a trend toward slight depression was evident with APV (Figure 2, +APV trace, $t_{(7)}=2.16$, $p=0.07)$, there was no significant difference between QUIN and APV treatment $\left(\mathrm{F}_{(1,17)}=0.97, p=0.33\right)$, suggesting both prevented potentiation without rescuing whole-cell depression. Co-administration of quinpirole and APV fully rescued LTD (Figure 2, QUIN+APV, $t_{(8)}=5.62, p<0.001$; QUIN $+\mathrm{APV}$ contrasted with cNIC controls, treatment $\times$ time, $\mathrm{F}_{(1,24)}=27.45, p<0.001 ; \mathrm{APV}+\mathrm{QUIN}$ and APV, $\mathrm{F}_{(1,15)}=$ $7.15, \quad p=0.017 ; \quad$ APV+QUIN and QUIN, $F_{(1,18)}=14.2$, $p<0.01$; full anova, treatment main effect, $\mathrm{F}_{(3,40)}=8.58$, $p<0.001$, treatment $\times$ time, $\left.\mathrm{F}_{(3,41)}=11.11, p<0.001\right)$.

\section{cNIC Alters Postsynaptic AMPA/NMDA Ratio in Striatopallidal MSNs}

To compare basal strength of synaptic transmission between cNIC and control mice, we assessed total evoked EPSC current at $+40 \mathrm{mV}$, which contains both AMPAR- and NMDAR-mediated components. Then AMPAR-mediated EPSCs $\left(\right.$ EPSC $_{\text {AMPA }}$ ) were pharmacologically isolated by bath application of APV $(50 \mu \mathrm{M})$ to block NMDAR-mediated EPSCs $\left(\right.$ EPSC $\left._{\text {NMDA }}\right)$. The EPSC NMDA $_{\text {was obtained by digital }}$ subtraction of EPSC $_{\mathrm{AMPA}}$ from the total current. Though total current was similar between groups, the cNIC mice exhibited a significantly decreased AMPA/NMDA ratio (Figure $3 \mathrm{a} / \mathrm{b}, \mathrm{F}_{(1,19)}=11.13, p<0.01$ ), reflecting both a trend toward increased NMDA (cNIC, 235.9 \pm 17.4 ; no-NIC, $\left.202.5 \pm 11.5, \mathrm{~F}_{(1,19)}=2.69, p=0.12\right)$ and decreased AMPA current (cNIC, $119.0 \pm 174.5 ;$ no-NIC, $181.2 \pm 16.5$, $\left.\mathrm{F}_{(1,19)}=7.83, p=0.012\right)$. In the cNIC-treated mice, we compared AMPA/NMDA ratio before and after HFS by measuring AMPA peak amplitude at $-70 \mathrm{mV}$ and measuring NMDAR amplitude $30 \mathrm{~ms}$ after the peak (total) current at $+40 \mathrm{mV}$. Following HFS, we observed an increase in AMPA current at $-70 \mathrm{mV}$ (pre-HFS, $262.0 \pm 15.1$; post-HFS, $\left.362.5 \pm 35.1, \mathrm{~F}_{(1,15)}=9.15, p<0.01\right)$, consistent with potentiation, and a trend toward increased NMDA current at +40 (pre-HFS, 65.8 $\pm 9.8 ;$ post-HFS, $97.0 \pm 17.2 ; \quad \mathrm{F}_{(1,15)}=2.4$, $p=0.14)$. However, we observe no significant change in AMPA/NMDA ratio (Figure 3c/d, pre-HFS, $4.94 \pm .89$; postHFS, $\left.4.37 \pm .59 ; \mathrm{F}_{(1,15)}=0.2, p=0.61\right)$. A concurrent increase 

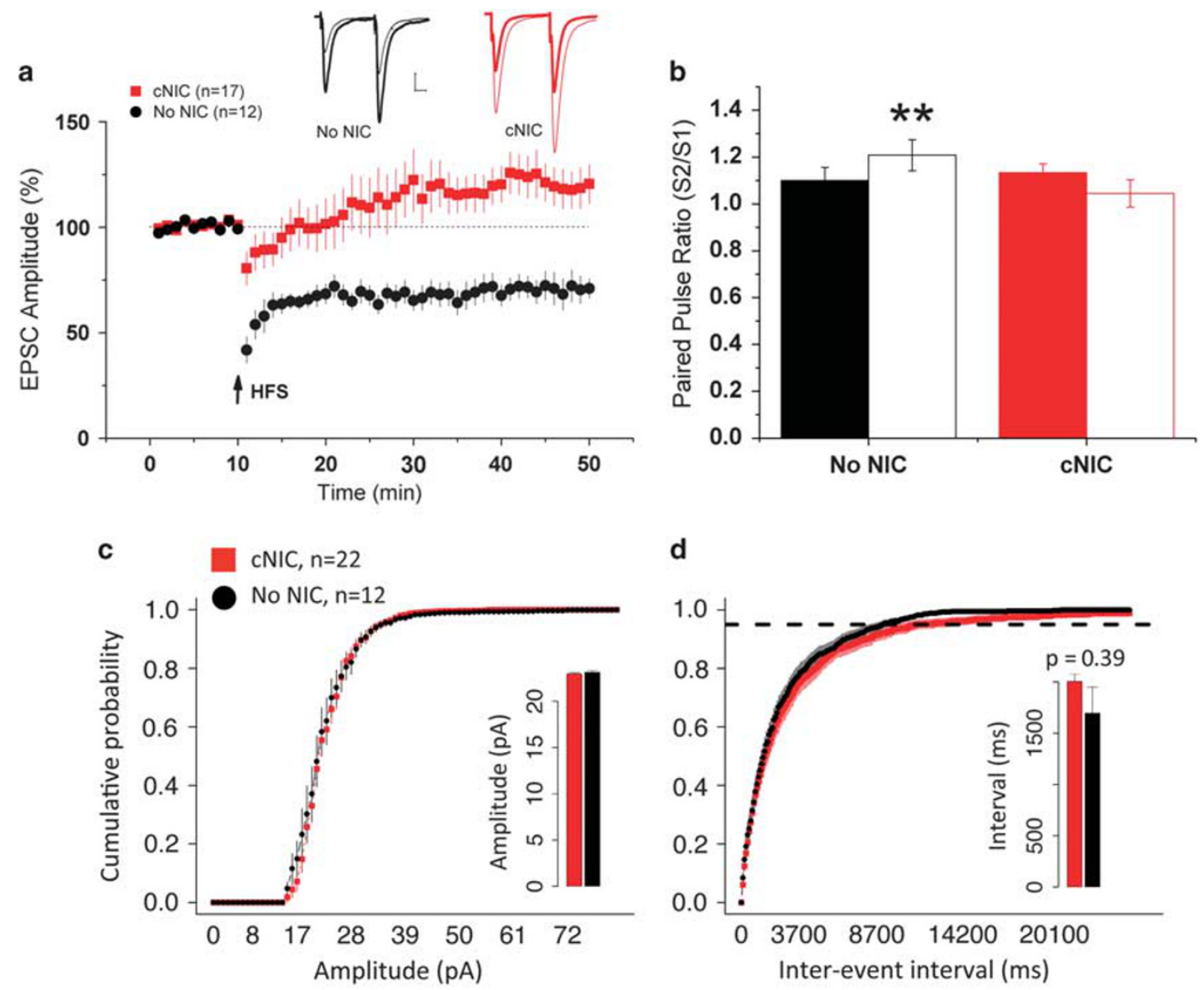

d

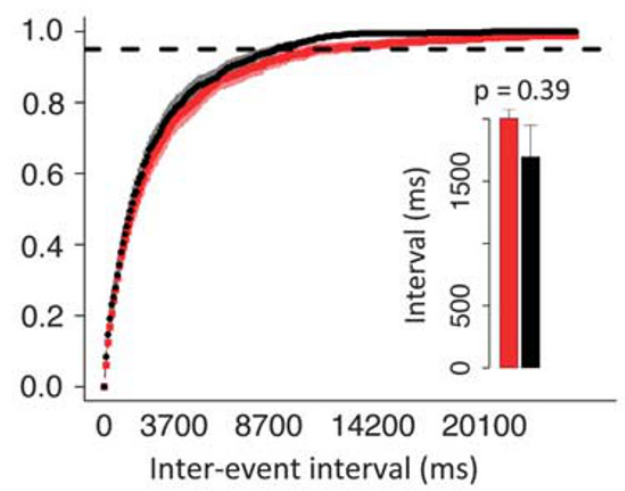

e $5 \mathrm{pA}$

Control

$240.0 \mathrm{~ms}$

CNIC
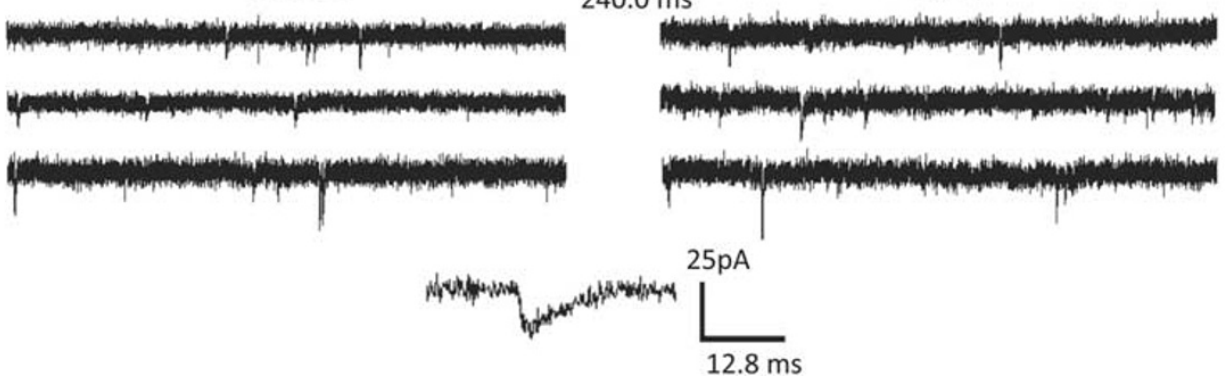

Figure I High-frequency stimulation induces LTP instead of LTD in striatopallidal MSNs in mice treated with cNIC. (a) Time course of EPSC amplitude normalized to baseline in response to HFS in non-NIC-treated controls (No NIC, black circles) and cNIC-treated group (red squares). Insets: representative traces before (thick line) and after (thin line) HFS. Arrows indicate HFS application. Scale bar: 20 ms, I00 pA. (b) Paired-pulse ratio before (solid bars) and after HFS (open bars) for non-NIC-treated controls (black) and cNIC mice (red). Cumulative probability distribution of (c) amplitude and (d) inter-event intervals comparing cells from non-NIC (black) and cNIC (red) mice from miniature EPSCs recorded at $-70 \mathrm{mV}$ holding potential (3 min samples). Dotted line in (d) denotes $95 \%$ of events. Insets: mean amplitude and inter-event interval, respectively. (e) Sample traces from mEPSC for control and cNIC mice and sample event. Data are presented as mean \pm SEM. *** $p<0.01$.

in both AMPAR and NMDAR currents could reflect increased postsynaptic function in both receptor types or presynaptic enhancement. With presynaptic enhancement, we would either expect comparable increases in AMPAR, NMDAR, and total (peak at +40) currents, in the absence of postsynaptic insertion of AMPARs, or disproportionately greater AMPA increases if presynaptic enhancement occurred in combination with AMPAR insertion. The percent increase following HFS in NMDAR current $(54 \pm 18 \%)$ was greater than the increase in either the AMPA at $-70 \mathrm{mV}$ $(38 \pm 11 \%)$ or the total peak current at $+40 \mathrm{mV}(28 \pm 11 \%$; Figure $3 \mathrm{~d}$ right, showing percent increase in total $v s \mathrm{NMDA}$ current for each cell, $\left.\mathrm{F}_{(1,8)}=8.62, p=0.018\right)$, suggesting differential postsynaptic changes in these currents rather than presynaptic enhancement, though the present data cannot rule out the possibility of presynaptic enhancement as 

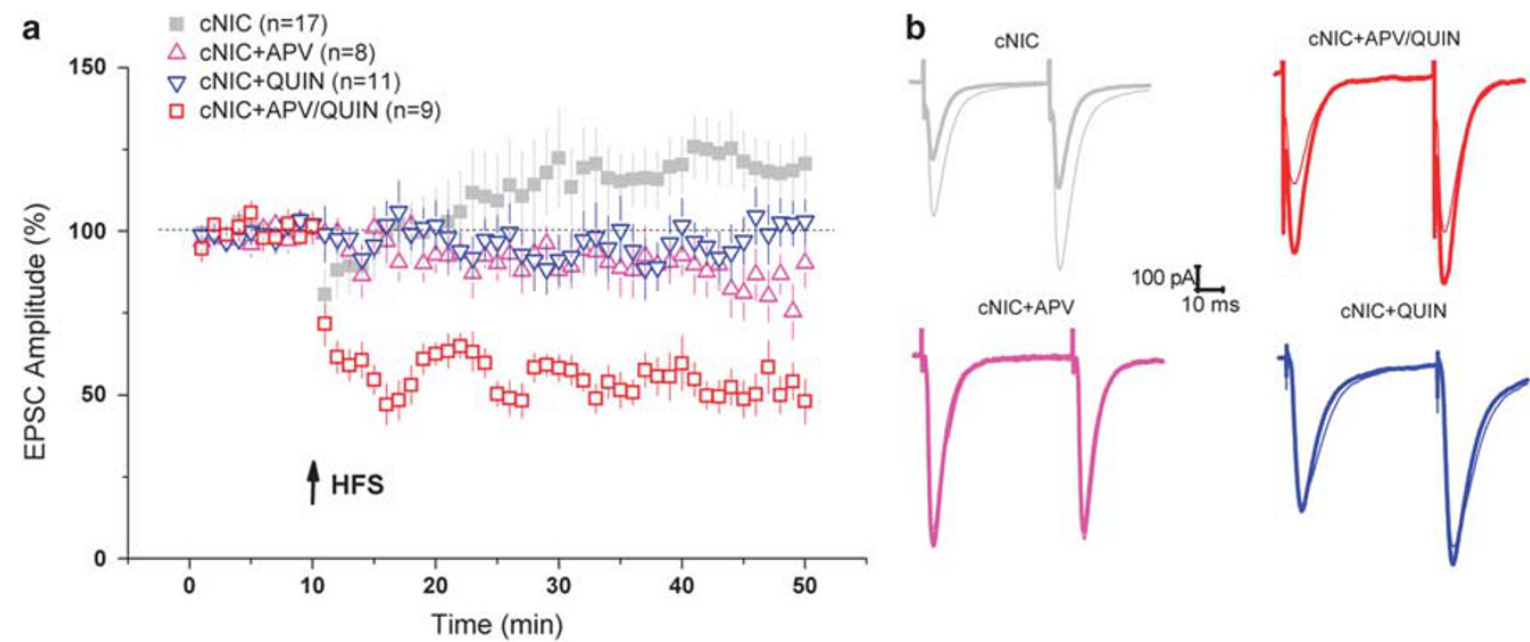

Figure 2 Pharmacological rescue of whole-cell HFS-LTD in cNIC-treated mice. (a) EPSC time course in cNIC-treated mice in the presence of quinpirole (QUIN, $10 \mu \mathrm{M}$, blue triangles), APV (APV, $50 \mu \mathrm{M}$, magenta triangles) and both quinpirole and APV co-applied (APV/Quin, red squares). cNIC HFS-LTP from Figure I re-plotted in light gray for reference. Arrows indicate HFS application. (b) Representative traces (same color coding) before (thick line) and after (thin line) HFS. Arrows indicate HFS application. Data are presented as mean \pm SEM.

well. Commonly, postsynaptic potentiation is mediated by AMPA insertion/trafficking, leading to an increase in AMPA (and total) current as well as an increase in the AMPA/ NMDA ratio. In cNIC-treated mice, we observed the expected increase in AMPA following HFS-LTP, but a concomitant increase in NMDA as well. These data suggest cNIC alters the regulation of NMDA receptors.

\section{cNIC Induces Enrichment in the NR2B Subunit}

We assessed changes to NMDA subunit composition, anticipating an upregulation of NR2B. A current-voltage curve ( -80 to $+40 \mathrm{mV}, 20 \mathrm{mV}$ steps) was constructed in the presence of $\mathrm{Mg}^{2+}(2 \mathrm{mM})$ with AMPA blocker NBQX in the bath $(5 \mu \mathrm{M})$ to assess NMDA-mediated EPSCs (EPSC $\left.{ }_{\mathrm{NMDAR}}\right)$, with and without the NR2B-selective antagonist Ro25-6981 $(1 \mu \mathrm{M})$ to determine the relative contribution of NR2B, comparing non-nicotine-treated control mice with cNIC-treated mice. In control mice, Ro25-6981 induced only modest change in current (Figure $4 \mathrm{a} / \mathrm{b}$; average reduction, $6.67 \pm 3.7 \%$; control mice \pm Ro25-6981, $F_{(1.9)}=13.2, p<0.01$ ), indicating only a minor NR2B contribution. In contrast, under cNIC, NR2B blockade induced a robust decrease in current and shift in the $\mathrm{I}-\mathrm{V}$ plot (Figure $4 \mathrm{a} / \mathrm{b}$; average reduction, $36.53 \pm 2.3 \%$; $c$ NIC mice \pm Ro25-6981, $\left.\mathrm{F}_{(1.7)}=22.35, p<0.01\right)$, with a significant difference between $\mathrm{cNIC}$ and control mice in response to Ro25-6981 (Figure 4b, cNIC/no-NIC $\times \pm$ Ro25$6981, \mathrm{~F}_{(1.16)}=37.6, \quad p<0.001$; average percent reduction, cNIC/no-NIC, $\quad \mathrm{F}_{(1.16)}=12.41, \quad p<0.01, \quad \mathrm{cNIC} /$ no-NIC $\times$ voltage, $\left.\mathrm{F}_{(1,106)}=8.09, p<0.01\right)$. As $\mathrm{NR} 2 \mathrm{~B}$ confers slower current decays, we evaluated time to $33 \%$ of peak current at $+40 \mathrm{mV}$, when NMDA is fully activated. While Ro25-6981 has little impact on decay in non-nicotine-treated mice (before, $108.8 \pm 4.33$; after, $101.9 \pm 4.02, p=0.25)$, it induces a substantial reduction (cNIC, before, 118.1 \pm 10.1 ; after, $87.9 \pm 7.9, p<0.05$ ) in the cNIC-treated mice (Figure $4 \mathrm{~b}$, inset, cNIC/no-NIC $\times \pm$ Ro25-6981, $\left.\mathrm{F}_{(1,16)}=10.78, p<0.01\right)$. These data suggest increased NR2B subunit expression in mice treated with $\mathrm{cNIC}$.
To test the contribution of NR2B in response to afferent stimulation, test pulses were applied every $20 \mathrm{~s}$ (plotted by $1 \mathrm{~min}$ average of three test pulses) at a holding potential of $-70 \mathrm{mV}$ in $\mathrm{Mg}^{2+}$-free ACSF during three phases: baseline (ACSF only, min 1-10), application of Ro25-6981 to selectively block NR2B (min 11-20), and application of NVP-AAM077 (50 nM) to additionally block NR2A (min 21-30), again with NBQX in the bath $(5 \mu \mathrm{M})$ to block AMPAR current. Under these conditions $\left(\mathrm{Mg}^{2+}\right.$-free, $-70 \mathrm{mV}$ ), application of Ro25-6981 in control mice mildly reduced EPSCs (Figure 4c) by $\sim 10 \%$ (Figure 3d). However, in cNIC mice, Ro25-6981 reduced EPSCs by $\sim 30 \%$, again suggesting cNIC induced enhanced NR2B expression (Figure $4 \mathrm{c} / \mathrm{d}$ and $\mathrm{c}, \mathrm{cNIC} / \mathrm{no}-\mathrm{NIC} \times$ time during Ro25-6981 treatment $(\min 10-20), \mathrm{F}_{(1,12)}=7.13, p<0.05 ; 3 \mathrm{D}$, final time point of each treatment, cNIC/no-NIC $\times$ treatment (only Ro25-6981 shown), $\left.\mathrm{F}_{(2,24)}=3.86, p<0.05\right)$. After application of NVP-AAM077 to additionally block NR2A, the residual current was slightly higher in cNIC mice (cNIC, $21.7 \pm 2.6$; no-NIC, 17.1 \pm .91 ), potentially suggesting alterations in other NMDA subunits, though this was not significant (last five time points, $\left.\mathrm{F}_{(1,12)}=0.491, p=0.49\right)$. These data suggest that cNIC treatment altered regulation of NMDA subunit composition inducing enriched NR2B expression.

\section{cNIC Increases Prevalence of NR2B-Containing Silent Synapses in Striatopallidal MSNs}

Both cocaine and morphine can induce the formation of silent synapses in MSNs (Graziane et al, 2016; Huang et al, 2009; Koya et al, 2012; Lee et al, 2013). Silent synapses contain NMDA but not AMPA receptors and thus, due to $\mathrm{Mg}^{2+}$ block of NMDA, are not activated by presynaptic glutamate release at resting membrane potentials, ie, in absence of postsynaptic depolarization. Silent synapses are associated with enriched NR2B subunits and, once activated or 'unsilenced,' the inserted AMPA receptors are frequently enriched with calcium-permeable, GluA2-lacking AMPA receptors (CP-AMPARs) (Graziane et al, 2016; Huang 
a

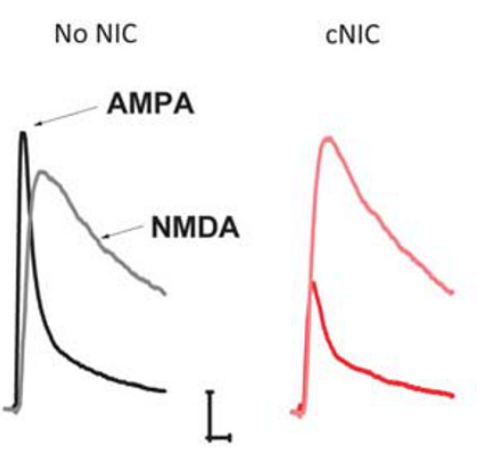

C

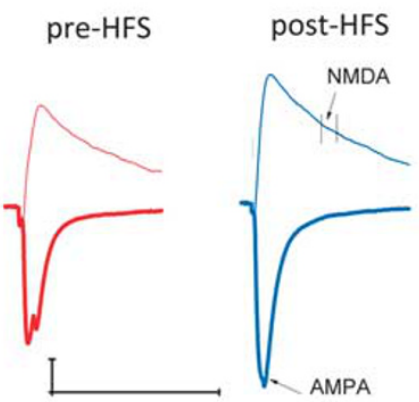

b

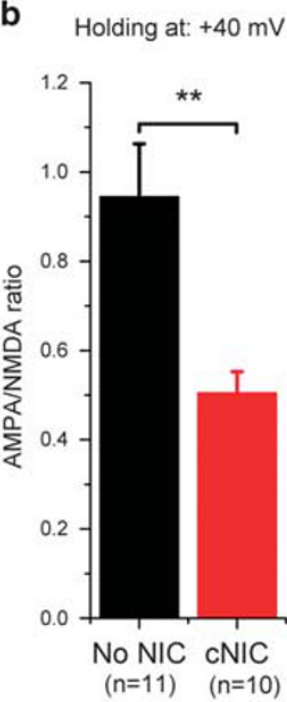

d

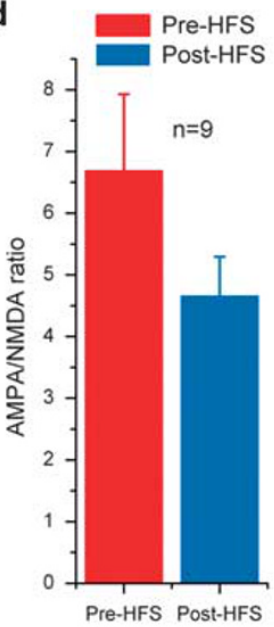

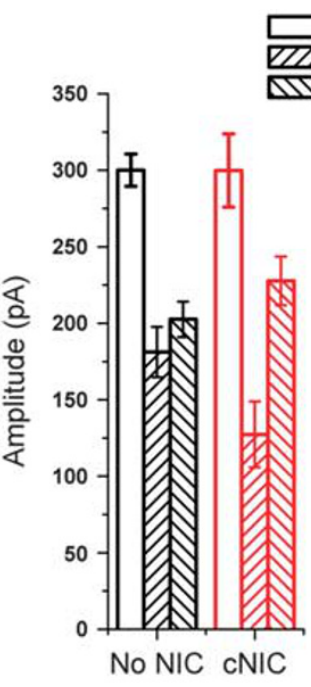

Total

AMPA

NMDA
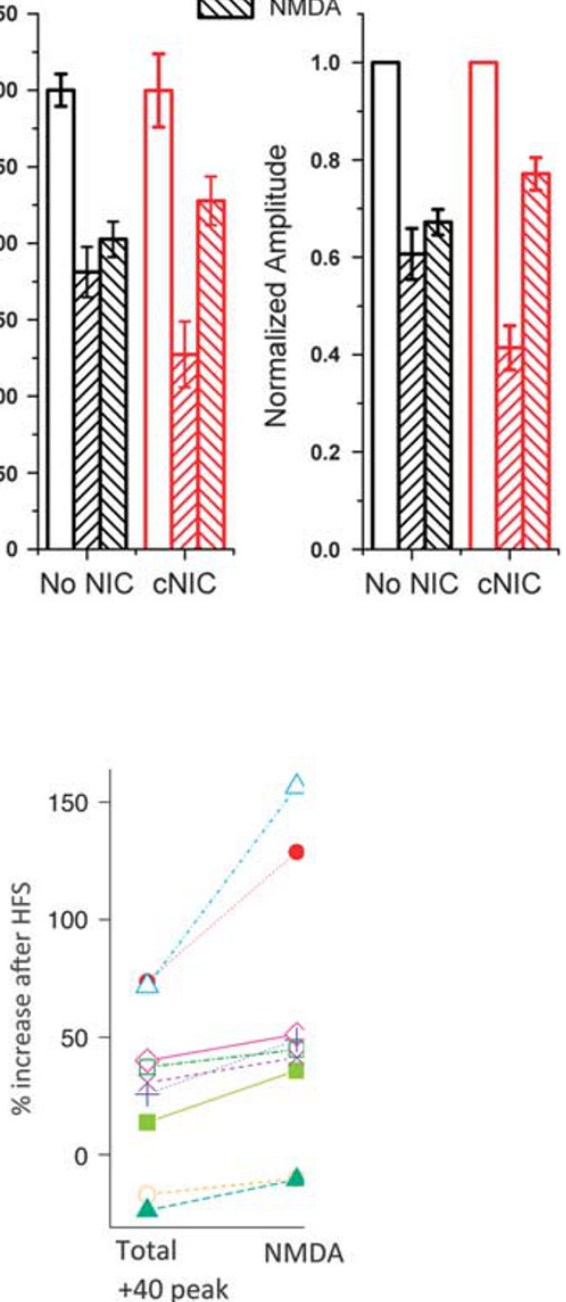

Figure 3 cNIC decreases AMPA/NMDA ratio. (a) Representative AMPA and NMDA traces pharmacologically isolated in non-NIC control and cNIC groups (controls, black, cNIC, red; light trace, NMDA, dark trace, AMPA). (b) Left: Bar graph of AMPA/NMDA ratio, middle: Bar graph of total, AMPA and NMDA current amplitudes, right: currents normalized to total current. (c) Representative traces of AMPA (dark trace, measured - $70 \mathrm{mV}$ ) and NMDA (light trace, measured $30 \mathrm{~ms}$ after AMPA peak at $+40 \mathrm{mV}$ ) current before (red) and after (blue) HFS in cNIC group. (d) Left: AMPA/NMDA ratio measured at $-70 /+40 \mathrm{mV}$ before and after HFS in cNIC group. Right: Comparing percent increase following HFS in total current (peak at +40) with increase in NMDA measured at $30 \mathrm{~ms}$ following peak current, plotted for each cell. Data are presented as mean \pm SEM. $* * * 0<0.01$.

et al, 2009; Lee et al, 2013; Ma et al, 2014). The enhanced NMDA current and enriched NR2B subunit composition suggest that cNIC may increase silent synapses that are activated by HFS, giving rise to LTP where normally LTD would be observed. To assess silent synapse prevalence, we used a minimal stimulation protocol (Huang et al, 2009; Marie et al, 2005) to measure the percentage synapses that contain NMDA only. Control mice exhibited a low percentage of silent synapses ( 15\%, Figures $5 \mathrm{a} / \mathrm{b})$, as previously observed (Brown et al, 2011; Graziane et al, 2016; Huang et al, 2009; Marie et al, 2005). In contrast, cNIC mice exhibited a dramatic increase in silent synapses, approaching 60\%. Applying Ro25-6981 during the assay eliminated the increased success rate at $+40 \mathrm{mV}$ in cNIC mice indicating that the majority of these silent synapses are NR2B-containing (Figure 5a/b, $F_{(2,21)}=10.54, p<0.001$ ).

Activating or 'unsilencing' NMDA-only synapses frequently includes the insertion of CP-AMPARs (Lee et al,
2013; Ma et al, 2014). To test for the presence of CP-AMPARs in the HFS-LTP observed in cNIC-treated mice, we induced LTP and subsequently bath applied Naspm $(100 \mu \mathrm{M})$, a selective blocker of CP-AMPARs. Twenty minutes following LTP induction, bath application of Naspm partially reduced the enhanced EPSCs (Figure $5 \mathrm{c} / \mathrm{d}$, before/ after Naspm (excluding baseline) $\times$ time point, $\mathrm{F}_{(1,302)}=$ 109.5, $p<0.001$, last five data points prior to Naspm (26-30) contrasted with last five after Naspm (46-50), $\mathrm{F}_{(1,54)}=9.2$, $p<0.01)$, suggesting the observed potentiation arises partially from insertion of CP-AMPARs. Thus, consistent with other drugs of abuse, cNIC increases the prevalence of silent synapses.

\section{DISCUSSION}

In these studies, we demonstrate that cNIC treatment induces significant changes in the regulation of corticostriatal plasticity 


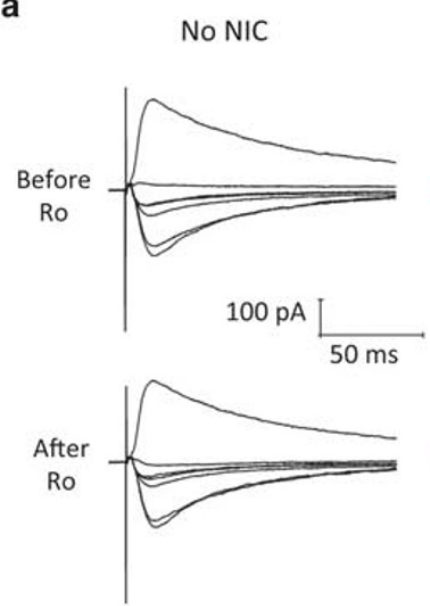

CNIC

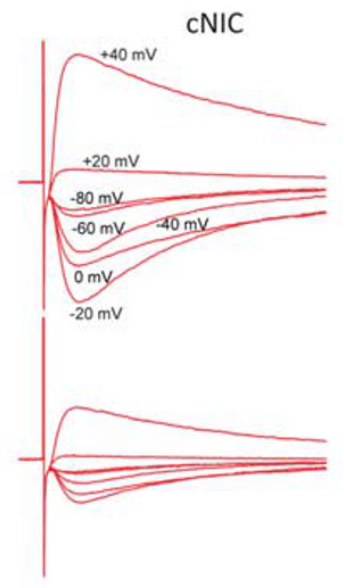

C
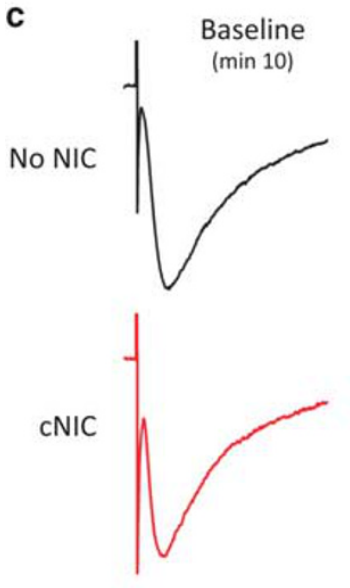
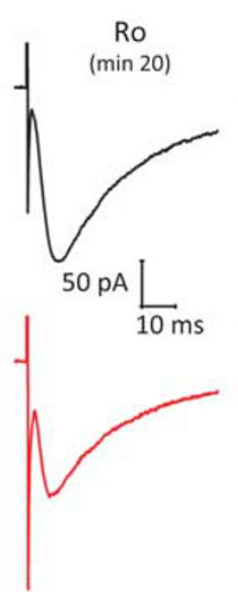

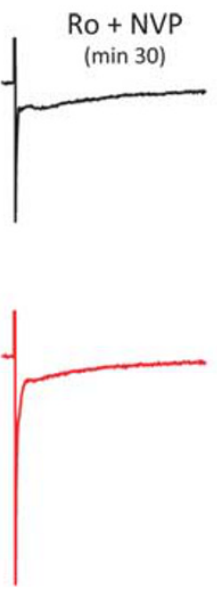

b
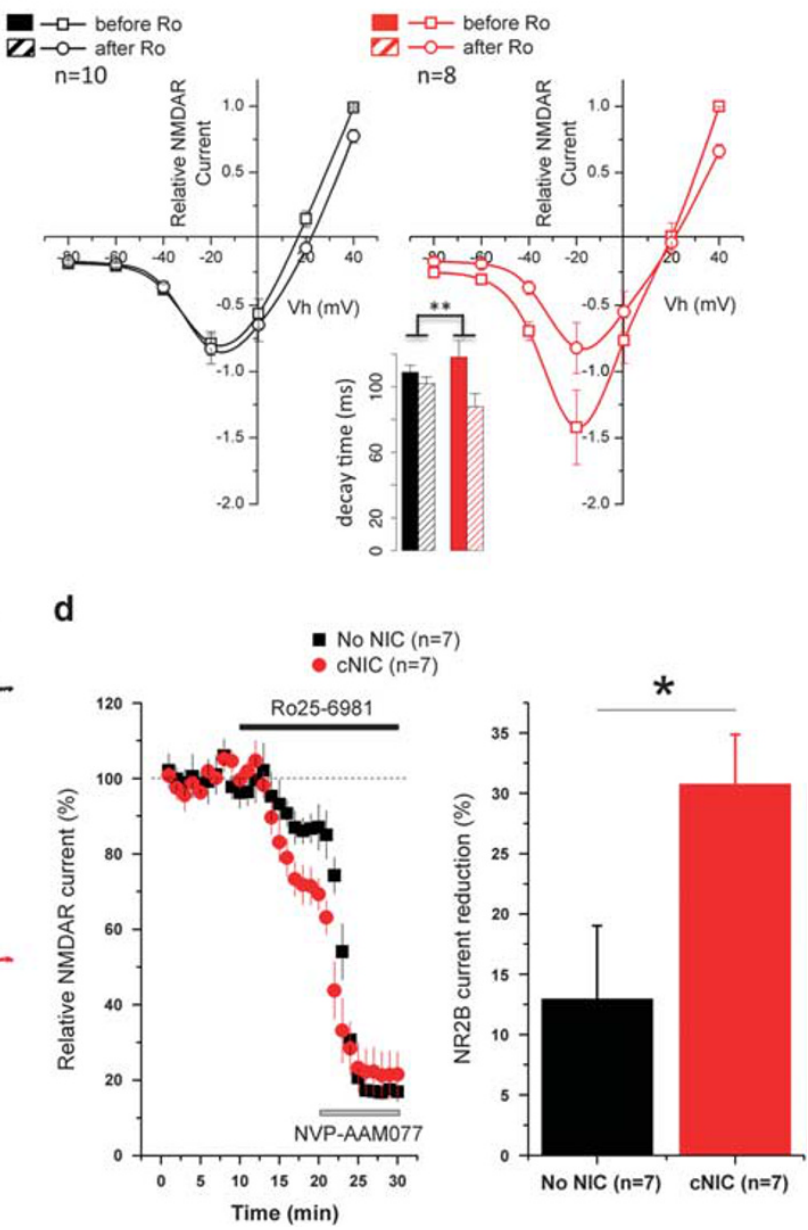

Figure 4 cNIC exposure increases NR2B-containing NMDAR current. (a) Representative traces of NMDA current induced at holding potentials from $-80 \mathrm{mV}$ to $+40 \mathrm{mV}$ in the absence and presence of Ro25-698I (I $\mu \mathrm{M})$ in non-NIC control and cNIC-treated mice with Mg${ }^{2+}$ (2 mM) in ACSF. (b) Currentvoltage (I-V) curve of NMDA current in the presence and absence of Ro25-698I in non-NIC-treated and cNIC-treated mice, normalized to current +40 mV. Inset: current decay (time to $33 \%$ peak current) measured at $+40 \mathrm{mV}$. (c) Representative traces of stimulated NMDA current at baseline, in the presence of Ro25-698 I (I MM), and Ro25-698I +NVP-AAM077 (50 nM) in non-NIC control (black traces) and cNIC-treated (red traces) groups, recorded at - 70 mV holding potential in $\mathrm{Mg}^{2+}$-free ACSF. (d) Left: time course of normalized NMDA current change in response to Ro25-698I and NVP-AAM077 perfusion in non-NIC control (black squares) and cNIC-treated (red circles) groups (holding potential $-70 \mathrm{mV}, \mathrm{Mg}^{2+}$-free ACSF). Right: bar graph of maximal NR2B current reduction under Ro25-698I perfusion. Data are presented as mean \pm SEM. $* p<0.05$, ** $p<0.01$.

in striatopallidal MSNs in the DLS. Although normally the application of HFS in a slice preparation induces a robust LTD in these cells, following cNIC treatment this same stimulation protocol induces LTP, effectively inverting the direction of plasticity. Inversion of HFS-LTD in striatopallidal cells has been observed previously under conditions of reduced dopamine or D2R knockout (Calabresi et al, 1997; Picconi et al, 2003; Shen et al, 2008). As cNIC diminishes dopamine release in mice and non-human primates (Koranda et al, 2014; Perez et al, 2012), this inversion is likely mediated by altered dopamine signaling.

The rescue experiments suggest a possible dissociation between the regulation of LTD and LTP induced by CNIC. Both quinpirole and APV block HFS-LTP in cNIC-treated mice without rescuing whole-cell LTD. Co-application of quinpirole and APV restores normal whole-cell HFS-LTD. One possibility is that quinpirole restores presynaptic depression without blocking postsynaptic potentiation, effectively canceling each other out. In contrast, APV may block postsynaptic potentiation without rescuing presynaptic depression. Co-administration of both restores normal function. Although it has been suggested that LTD and LTP may, theoretically, occur simultaneously (Lovinger, 2010), it is generally presumed that in bidirectional regulation of corticostriatal plasticity these mechanisms are coupled, most likely co-regulated by cAMP/PKA (Augustin et al, 2014; Lerner and Kreitzer, 2011), though regulation of LTD and LTP may diverge downstream of PKA (Tashev et al, 2009). Under cNIC, this coordinated regulation may become uncoupled.

Dysregulation of corticostriatal plasticity may arise secondary to a cNIC-induced upregulation in silent synapses. Silent, NMDA-only synapses are prevalent during early development and provide a rich substrate from which synapses are selected or pruned to form functional neural circuits; however, they are almost entirely absent in 


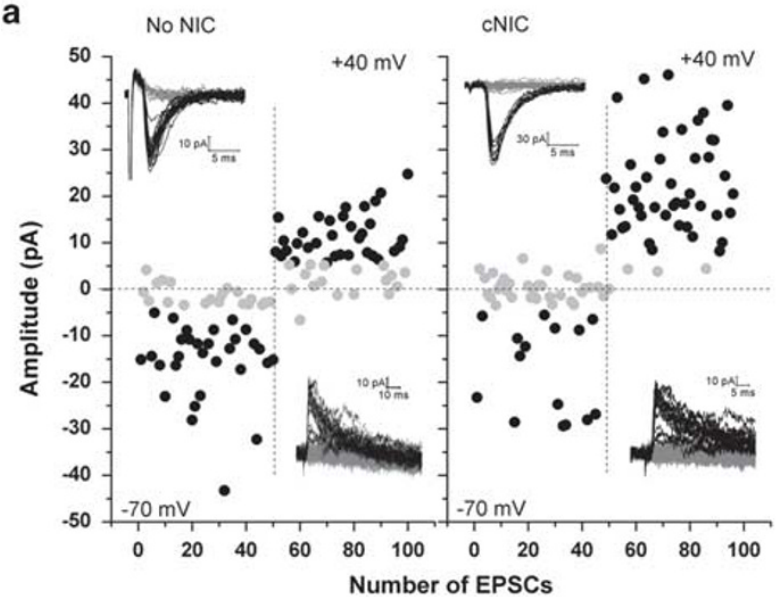

C

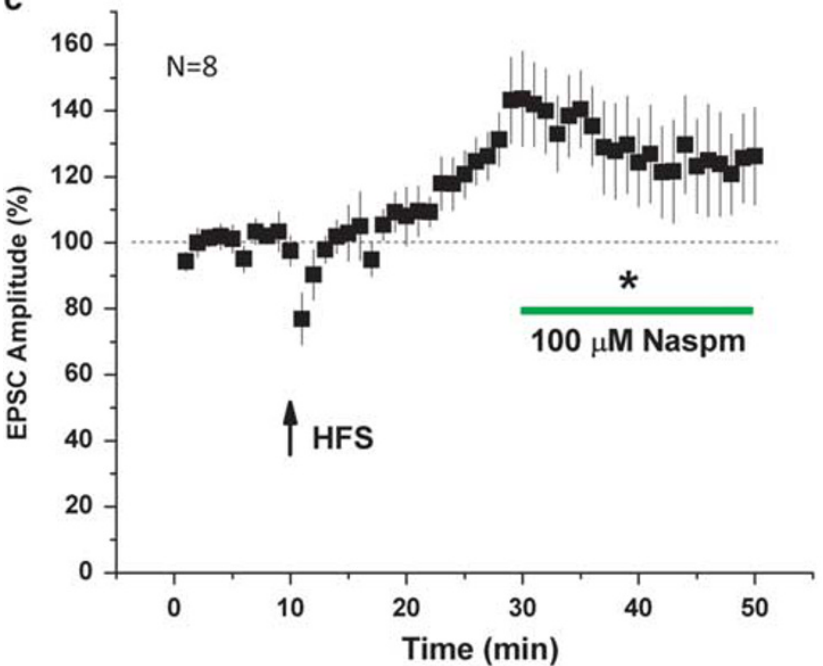

b

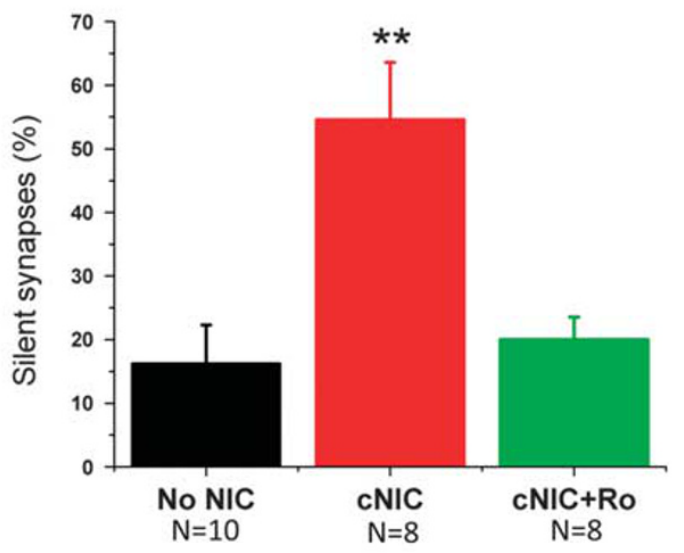

d

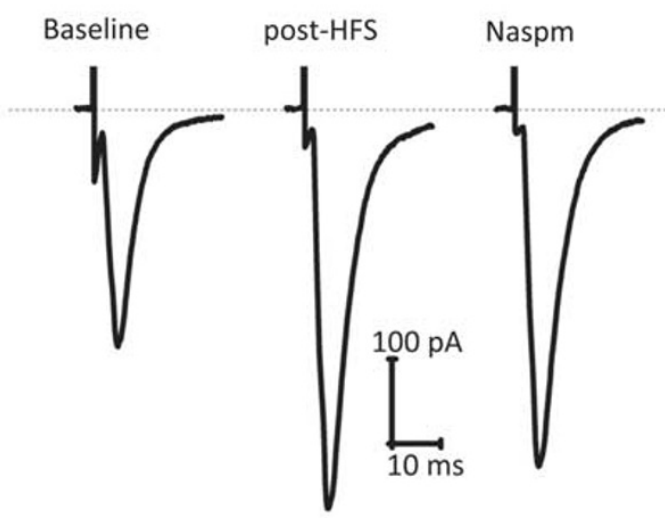

Figure 5 Exposure to $\mathrm{CNIC}$ generates NR2B-enriched silent synapses. (a) Example plot of EPSC amplitude evoked by minimal stimulation assay at - 70 and $+40 \mathrm{mV}$ (50 consecutive trials each) in non-NIC-treated and cNIC-treated mice. Black dots indicate successful response, gray dots indicate failure. Insets: current traces from individual trials of representative plots. (b) Average percentage of silent synapses in non-NIC-treated (black bar), cNIC-treated (red bar) and cNIC treat with Ro25-698I (I HM) application (green bar). (c) EPSC amplitude in response to HFS (arrow) and subsequent application of Naspm $(\mathrm{I} 00 \mathrm{\mu M}$ ) in cNIC-treated mice. (d) Representative traces of EPSC at baseline, after HFS and following Naspm perfusion, as shown in (c). Data are presented as mean \pm SEM. $*$ p $<0.05$, *** $<0.01$.

adulthood (Hanse et al, 2013). In recent years, studies have demonstrated that both cocaine and opiates can induce an upregulation of silent synapses in MSNs (Dong and Nestler, 2014). More recently, Graziano et al (2016) have demonstrated that cocaine and opiates upregulate silent synapses selectively in direct and indirect pathway MSNs, respectively, via two different mechanisms. Cocaine increases silent synapses via upregulation of the NR2B NMDA subunits and the creation of new synapses while opiates increase silent synapses through the removal of AMPARs from extant, previously non-silent synapses.

We demonstrate for the first time that $\mathrm{cNIC}$ can upregulate silent synapses in MSNs. Prior work on silent synapses and drugs of abuse have all examined MSNs in the NAc (Brown et al, 2011; Graziane et al, 2016; Huang et al, 2009; Koya et al, 2012; Lee et al, 2013; Ma et al, 2014; Whitaker et al, 2015). The DLS, however, is believed to be a crucial substrate during later stages of addiction and central to cravings and reinstatement of drug-seeking that compromise abstinence (Everitt and
Robbins, 2016; Gerdeman et al, 2003). We show here that exposure to cNIC, and likely other drugs of abuse, can upregulate silent synapses in the dorsal striatum. Similar to cocaine's regulation of silent synapses, we observe (a) a decrease in AMPA/NMDA ratio at baseline, arising from enhanced NMDAR expression, (b) enrichment in NR2B subunit expression, and (c) NR2B enrichment specifically in silent synapses. Together, these data indicate that cNIC induces an upregulation of silent synapses via the creation of new NR2B-enriched synapses, similar to cocaine (Graziane et al, 2016; Huang et al, 2009). However, unlike cocaine, cNIC induces this upregulation in striatopallidal MSNs. Thus, it appears that the effects of cNIC on silent synapse induction is distinct from both cocaine and opiates, inducing the mechanism associated with cocaine while affecting the cell population and pathway affected by opiates, though we did not examine the effects of cNIC on striatonigral cells in this study.

Our findings are consistent with prior studies that observed cNIC induced increases in NMDA function, including NR2B 
current and phosphorylation at tyrosine 1472, in the hippocampus, PFC, and NAc (Ávila-Ruiz et al, 2014; Nakajima et al, 2012; Yamazaki et al, 2006) as well as increased LTP in the hippocampus (Yamazaki et al, 2006) and amygdala (Huang et al, 2008). Increased CREB activity alone can induce an upregulation of silent synapses (Brown et al, 2011; Marie et al, 2005). Nicotine can induce upregulation of CREB (Brunzell et al, 2003). cNIC can reduce phosphodiesterase activity (Polesskaya et al, 2007), potentially elevating cAMP and increasing PKA activity and downstream CREB activation. Finally, cNIC can increase cFOS activity in the caudate putamen (Marttila et al, 2006), potentially contributing to changes in synaptic plasticity observed here. The mechanisms underlying the observed neuroadaptations in response to cNIC remain to be elucidated.

In a recent report, Abburi et al (2016) show that pretreatment with nicotine $(1 \times /$ day, 3 days $)$ resulted in increased paired-pulse facilitation in striatopallidal MSNs of the DLS. They further show nicotine pretreatment blocked the ability of Win55-2-212 to induce presynaptic depression, suggesting that nicotine pretreatment induces a widespread presynaptic depression in striatopallidal MSNs. We did not observe this presynaptic depression at baseline (pre-stimulation) between our cNIC mice and controls (Figure $1 \mathrm{~b}$ and $\mathrm{d}$ ). The most likely explanation is the difference between subchronic (Aburri et al, three injections total) and chronic (here, 3 weeks continual, intermittent access via drinking water). Cocaine-induced upregulation of silent synapses occurs gradually over a period of 3-5 consecutive administrations (Huang et al, 2009). Thus, it is likely that the increased presynaptic depression observed by Aburri et al represents an early stage adaptation in response to nicotine, while the robust upregulation of silent synapses and associated HFS-LTP we observe arises following extended nicotine exposure. In addition, the route of administration (injection, drinking water) and frequency $(1 \times /$ day, intermittent $)$ may account for differences, though the duration of exposure is likely most critical.

How the upregulation of silent synapses may contribute to addiction is not understood. Elegant studies have linked silent synapses to incubation (Lee et al, 2013; Ma et al, 2014), a phenomenon where the strength of drug craving increases rather than diminishes in the months following abstinence. However, this linkage is complicated. First, cocaine-induced silent synapse upregulation normalizes within 7-10 days following drug discontinuation (Koya et al, 2012), making it difficult to understand how a neuroadaptation that normalizes upon drug discontinuation can have effects months later. Recent studies have suggested that drug-induced regulation of silent synapses may be neural activity-dependent (Koya et al, 2012; Whitaker et al, 2015). For example, it has been demonstrated that MSNs selectively activated during noncontingent cocaine administration can exhibit silent synapse upregulation in response to cocaine challenge after 45 days of abstinence, long after the generalized upregulation of silent synapses has normalized (Koya et al, 2012), though because this was non-contingent cocaine administration, it remains unclear from these data how this phenomenon may contribute to incubation. In a study that directly examined the contribution of silent synapses to incubation, $\mathrm{Ma}$ et al (2014) demonstrate that silent synapse activation/resilencing in different pathways can contribute both to facilitating and diminishing drug reinstatement. These and other published data, collectively, indicate that drug-induced induction of silent synapses contributes to addiction, and specifically incubation of craving upon drug discontinuation, though the role silent synapses play remains unclear.

A critical aspect of understanding the role of silent synapse upregulation in addiction will be understanding how corticostriatal plasticity and learning is subsequently altered. This question has not been examined in prior work investigating silent synapses and drugs of abuse, with the exception of demonstrating that low-frequency stimulation can resilence activated silent synapses (Lee et al, 2013; Ma et al, 2014), inducing a postsynaptic form of LTD. We show here that upregulation of silent synapses dramatically alters canonical striatal LTD induced in iMSNs by HFS, suggesting that cNIC can change ongoing striatal learning. Studies with cocaine and opiates have assessed silent synapses 1-2 days following discontinuation of drug administration, reflecting an early withdrawal state. In contrast, here mice are maintained on intermittent cNIC. Like smoking, this likely induces cycles of transient withdrawal and restabilizing drug ingestion; however, data suggest intermittent, prolonged administration also induces persistent neuroadaptations independent of transient states of withdrawal (McClernon et al, 2005; Rose et al, 2013). In our tests, we kill mice in the morning, without an explicit withdrawal period. Thus, although the mice may be in a transient state of withdrawal (analogous to a smoker being woken shortly after going to sleep), it is likely that absent prolonged withdrawal (greater than a few hours, see (Pluzarev and Pandey, 2004), this state reflects persistent neuroadaptations and, possibly, a state of transient withdrawal representative of a normal, recurrent state in nicotine addiction.

How this alteration in corticostriatal plasticity contributes to addiction, or for that matter to behavior generally, cannot be surmised from the current data. Activated silent synapses are generally labile (Hanse et al, 2013). Once AMPARs are inserted-often calcium-permeable (CP-AMPARs)-they can either be selected and stabilized ('matured') or resilenced. The mechanisms that regulate the selection/ stabilization ( $v s$ resilencing) of activated silent synapses in MSNs are not understood. Moreover, how these regulatory mechanisms overlap with or are distinct from mechanisms regulating synaptic plasticity of extant, non-silent synapses is unknown. Our data are the first to examine how normal corticostriatal plasticity is altered by drug-induced upregulation of silent synapses, suggesting avenues for future investigation.

\section{FUNDING AND DISCLOSURE}

This work was supported by NINDS R21NS083578 (JAB). The authors declare no conflict of interest.

\section{ACKNOWLEDGMENTS}

We thank David Lovinger for his advice and feedback throughout this work. We thank Joshua Brumberg for his troubleshooting assistance. 


\section{REFERENCES}

Abburi C, Wolfman SL, Metz RAE, Kamber R, McGehee DS, McDaid J (2016). Tolerance to Ethanol or nicotine results in increased ethanol self-administration and long-term depression in the dorsolateral striatum. eNeuro 3: ENEURO.0112-15.

Augustin SM, Beeler JA, McGehee DS, Zhuang X (2014). Cyclic AMP and afferent activity govern bidirectional synaptic plasticity in striatopallidal neurons. J Neurosci 34: 6692-6699.

Ávila-Ruiz T, Carranza V, Gustavo L-L, Limón DI, Martínez I, Flores G et al (2014). Chronic administration of nicotine enhances NMDA-activated currents in the prefrontal cortex and core part of the nucleus accumbens of rats: chronic administration of nicotine and NMDA currents. Synapse 68: 248-256.

Bagetta V, Picconi B, Marinucci S, Sgobio C, Pendolino V, Ghiglieri $\mathrm{V}$ et al (2011). Dopamine-dependent long-term depression is expressed in striatal spiny neurons of both direct and indirect pathways: implications for Parkinson's disease. J Neurosci 31: 12513-12522.

Brown TE, Lee BR, Mu P, Ferguson D, Dietz D, Ohnishi YN et al (2011). A silent synapse-based mechanism for cocaine-induced locomotor sensitization. J Neurosci 31: 8163-8174.

Brunzell DH, Russell DS, Picciotto MR (2003). In vivo nicotine treatment regulates mesocorticolimbic CREB and ERK signaling in C57Bl/6J mice. J Neurochem 84: 1431-1441.

Caggiula AR, Donny EC, White AR, Chaudhri N, Booth S, Gharib MA et al (2001). Cue dependency of nicotine self-administration and smoking. Pharmacol Biochem Behav 70: 515-530.

Calabresi P, Saiardi A, Pisani A, Baik J-H, Centonze D, Mercuri NB et al (1997). Abnormal synaptic plasticity in the striatum of mice lacking dopamine D2 receptors. J Neurosci 17: 4536-4544.

Choi S, Lovinger DM (1997). Decreased probability of neurotransmitter release underlies striatal long-term depression and postnatal development of corticostriatal synapses. Proc Natl Acad Sci USA 94: 2665-2670.

Dani JA, Ji D, Zhou F-M (2001). Synaptic plasticity and nicotine addiction. Neuron 31: 349-352.

Di Chiara G (2000). Role of dopamine in the behavioural actions of nicotine related to addiction. Eur J Pharmacol 393: 295-314.

Dong Y, Nestler EJ (2014). The neural rejuvenation hypothesis of cocaine addiction. Trends Pharmacol Sci 35: 374-383.

Everitt BJ, Robbins TW (2016). Drug addiction: updating actions to habits to compulsions ten years on. Annu Rev Psychol 67: 23-50.

Exley R, Clements Ma, Hartung H, Mcintosh JM, Franklin M, Bermudez I et al (2013). Striatal dopamine transmission is reduced after chronic nicotine with a decrease in a6-nicotinic receptor control in nucleus accumbens. Eur J Neurosci 38: 3036-3043.

Gerdeman GL, Partridge JG, Lupica CR, Lovinger DM (2003). It could be habit forming: drugs of abuse and striatal synaptic plasticity. Trends Neurosci 26: 184-192.

Graziane NM, Sun S, Wright WJ, Jang D, Liu Z, Huang YH et al (2016). Opposing mechanisms mediate morphine- and cocaineinduced generation of silent synapses. Nat Neurosci 19: 915-925.

Hanse E, Seth H, Riebe I (2013). AMPA-silent synapses in brain development and pathology. Nat Rev Neurosci 14: 839-850.

Huang YH, Lin Y, Mu P, Lee BR, Brown TE, Wayman G et al (2009). In vivo cocaine experience generates silent synapses. Neuron 63: 40-47.

Huang Y-Y, Kandel ER, Levine A (2008). Chronic nicotine exposure induces a long-lasting and pathway-specific facilitation of LTP in the amygdala. Learn Mem 15: 603-610.

Hyman SE, Malenka RC, Nestler EJ (2006). Neural mechanisms of addiction: the role of reward-related learning and memory. Annu Rev Neurosci 29: 565-598.

Kim J, Alger BE (2001). Random response fluctuations lead to spurious paired-pulse facilitation. J Neurosci 21: 9608-9618.
Klanker M, Feenstra M, Denys D (2013). Dopaminergic control of cognitive flexibility in humans and animals. Front Neurosci 7: 201. Koranda JL, Cone JJ, McGehee DS, Roitman MF, Beeler JA, Zhuang X (2014). Nicotinic receptors regulate the dynamic range of dopamine release in vivo. J Neurophysiol 111: 103-111.

Koranda JL, Krok AC, Xu J, Contractor A, McGehee DS, Beeler JA et al (2016). Chronic nicotine mitigates aberrant inhibitory motor learning induced by motor experience under dopamine deficiency. J Neurosci 36: 5228-5240.

Koya E, Cruz FC, Ator R, Golden SA, Hoffman AF, Lupica CR et al (2012). Silent synapses in selectively activated nucleus accumbens neurons following cocaine sensitization. Nat Neurosci 15: $1556-1562$.

Kreitzer AC, Malenka RC (2007). Endocannabinoid-mediated rescue of striatal LTD and motor deficits in Parkinson's disease models. Nature 445: 643-647.

Kreitzer AC, Malenka RC (2008). Striatal plasticity and basal ganglia circuit function. Neuron 60: 543-554.

Lee BR, Ma Y-Y, Huang YH, Wang X, Otaka M, Ishikawa M et al (2013). Maturation of silent synapses in amygdala-accumbens projection contributes to incubation of cocaine craving. Nat Neurosci 16: 1644-1651.

Lerner TN, Kreitzer AC (2011). Neuromodulatory control of striatal plasticity and behavior. Curr Opin Neurobiol 21: 322-327.

Lerner TN, Kreitzer AC (2012). RGS4 is required for dopaminergic control of striatal LTD and susceptibility to Parkinsonian motor deficits. Neuron 73: 347-359.

Lovinger DM (2010). Neurotransmitter roles in synaptic modulation, plasticity and learning in the dorsal striatum. Neuropharmacology 58: 951-961.

Mansvelder HD, McGehee DS (2000). Long-term potentiation of excitatory inputs to brain reward areas by nicotine. Neuron 27: 349-357.

Marie H, Morishita W, Yu X, Calakos N, Malenka RC (2005). Generation of silent synapses by acute in vivo expression of CaMKIV and CREB. Neuron 45: 741-752.

Marttila K, Raattamaa H, Ahtee L (2006). Effects of chronic nicotine administration and its withdrawal on striatal FosB/ $\Delta$ FosB and c-Fos expression in rats and mice. Neuropharmacology 51: 44-51.

Matta SG, Balfour DJ, Benowitz NL, Boyd RT, Buccafusco JJ, Caggiula AR et al (2007). Guidelines on nicotine dose selection for in vivo research. Psychopharmacology 190: 269-319.

Ma Y-Y, Lee BR, Wang X, Guo C, Liu L, Cui R et al (2014). Bidirectional modulation of incubation of cocaine craving by silent synapse-based remodeling of prefrontal cortex to accumbens projections. Neuron 83: 1453-1467.

McClernon FJ, Hiott FB, Huettel SA, Rose JE (2005). Abstinenceinduced changes in self-report craving correlate with eventrelated FMRI responses to smoking cues. Neuropsychopharmacology 30: 1940-1947.

Nakajima A, Kinugasa Y, Torii J, Hishinuma T, Tomioka Y, Yamada $\mathrm{K}$ et al (2012). Repeated treatment with nicotine induces phosphorylation of NMDA receptor NR2B subunit in the brain regions involved in behavioral sensitization. Neurosci Lett 524: 133-138.

Perez XA, Ly J, McIntosh JM, Quik M (2012). Long-term nicotine exposure depresses dopamine release in nonhuman primate nucleus accumbens. J Pharmacol Exp Ther 342: 335-344.

Picconi B, Centonze D, Håkansson K, Bernardi G, Greengard P, Fisone $G$ et al (2003). Loss of bidirectional striatal synaptic plasticity in L-DOPA-induced dyskinesia. Nat Neurosci 6: 501-506.

Pierce JP, Cummins SE, White MM, Humphrey A, Messer K (2012). Quitlines and nicotine replacement for smoking cessation: do we need to change policy? Annu Rev Public Health 33: $341-356$ 
Pluzarev O, Pandey SC (2004). Modulation of CREB expression and phosphorylation in the rat nucleus accumbens during nicotine exposure and withdrawal. J Neurosci Res 77: 884-891.

Polesskaya OO, Smith RF, Fryxell KJ (2007). Chronic nicotine doses down-regulate PDE4 isoforms that are targets of antidepressants in adolescent female rats. Biol Psychiatry 61: 56-64.

Rose EJ, Ross TJ, Salmeron BJ, Lee M, Shakleya DM, Huestis MA et al (2013). Acute nicotine differentially impacts anticipatory valenceand magnitude-related striatal activity. Biol Psychiatry 73: 280-288.

Shen W, Flajolet M, Greengard P, Surmeier DJ (2008). Dichotomous dopaminergic control of striatal synaptic plasticity. Science 321: 848-851.

Smolka MN, Bühler M, Klein S, Zimmermann U, Mann K, Heinz A et al (2006). Severity of nicotine dependence modulates cueinduced brain activity in regions involved in motor preparation and imagery. Psychopharmacology 184: 577-588.

Surmeier DJ, Graves SM, Shen W (2014). Dopaminergic modulation of striatal networks in health and Parkinson's disease. Curr Opin Neurobiol 29: 109-117.
Tashev R, Moura PJ, Venkitaramani DV, Prosperetti C, Centonze $\mathrm{D}$, Paul $\mathrm{S}$ et al (2009). A substrate trapping mutant form of striatal-enriched protein tyrosine phosphatase prevents amphetamine-induced stereotypies and long-term potentiation in the striatum. Biol Psychiatry 65: 637-645.

US Department of Health and Human Services (2014). The health consequences of smoking-50 years of progress. A report of the Surgeon General. https://www.surgeongeneral.gov/library/reports/ 50-years-of-progress/full-report.pdf.

Whitaker LR, Carneiro de Oliveira PE, McPherson KB, Fallon RV, Planeta CS, Bonci A et al (2015). Associative learning drives the formation of silent synapses in neuronal ensembles of the nucleus accumbens. Biol Psychiatry 80: 246-256.

Yamazaki Y, Jia Y, Niu R, Sumikawa K (2006). Nicotine exposure in vivo induces long-lasting enhancement of NMDA receptor-mediated currents in the hippocampus: chronic nicotine and synaptic plasticity. Eur J Neurosci 23: 1819-1828.

Yin HH, Knowlton BJ (2006). The role of the basal ganglia in habit formation. Nat Rev Neurosci 7: 464-476. 